\title{
Is It Possible to Apply Multidimensional Graphical Methods in The Teaching and Learning of Economics?
}

\author{
Mario Arturo Ruiz Estrada ${ }^{1}$
}

\begin{abstract}
This article explores the effectiveness of applying a new multidimensional graphical method to the teaching and learning of economics. In essence, the paper extends the significance of multi-dimensional graphs to study any economic phenomenon from a multidimensional perspective. The paper proposes the introduction of a new set of multidimensional coordinate spaces that should clearly and logically propose the effective visualization of complex and dynamic economic phenomena into the same graphical space and time with which the effectiveness of multidimensiona graphs for real practical purposes can be evaluated. From the analyses carried out, which are based on both primary and secondary data sources, the article argues that multidimensional graphs can actually be evaluated to understand the degree of their effectiveness in visualizing economic problems affecting society on different levels.
\end{abstract}

KEY WORDS: $\quad$ multidimensional graphs; economics teaching; GDP graphical analysis

JEL Classification: $\quad$ A22; A23; CO2; B41; E00

${ }^{1}$ University of Malaya, Malaysia

\section{The Evolution of Graphical Methods in Economics}

Research leading to this paper shows a strong link between the introduction of graphical methods in economics and the development of theories, methods and techniques in statistics and mathematics. In the $18^{\text {th }}$ century, for example, several new graphical methods were developed as a result of contemporary advances in mathematics and statistics research (Gordon, 1965). These graphical methods include line graphs of time series data (since 1724), curve fitting and interpolation (1760), measurement of error as a deviation from

Correspondence concerning this article should be addressed to: Mario Arturo Ruiz Estrada, University of Malaya, Faculty of Economics and Administration, 50603 Kuala Lumpur, MALAYSIA. E-mail:marioruiz@um.edu.my graphed line (1765), graphical analysis of periodic variation (1779), statistical mapping (1782), bar charts (1756) and printed coordinate paper (1794) (Beniger \& Robyn, 1978). For the application of graphical methods in economic analysis, we can look to the renowned economists such as William Playfair (2005), Francis Ysidro Edgeworth (1888) and William Stanley Jevons (1862). According to Harro Maas (2005), William Playfair constructed a wonderful collection of plates and graphs at the end of the $18^{\text {th }}$ century. In his book entitled Commercial and Political Atlas, Playfair focused on the study of trade cycles. This placed him far ahead of other economists at the time in terms of visualizing socioeconomic data.

The development of the usage of graphical methods in economics can be classified into two distinct phases. The first phase is the descriptive graphical method. It is supported by simple tables, histograms, line graphs 
and scatter plots. These types of graphs are based on the visualization of a single economic variable (vertical axis $=\mathrm{Y}$ ) through a specific period of time (horizontal axis $=\mathrm{X}$ ) in the first quadrant in the two-dimensional Cartesian coordinate system (see Figure 1). The main objective of the descriptive graphical method in economics is to study the behavior of a single economic variable (e.g., exports, imports, unemployment, GDP, inflation rate) within a time frame (per decade, annually, monthly, weekly or daily) based on time series. In fact, William Playfair may be considered the pioneer and promoter of the descriptive graphical method. The second phase in the development of graphical methods for economics is the "analytical graphical method". The analytical graphical method in economics is distinguished by the use of 2-dimensional and 3-dimensional coordinate systems. According to Harro Maas, it was William Stanley Jevons who first explored the merits of the graphical method for political economy. Jevons did this using a function called the "King-Devenant Law of Demand," which he pioneered. This is a case of the use of analytical graphical method in economics, where the form of the graph gives an idea of the possible class of the functions describing the relationship between $\mathrm{X}$ and $\mathrm{Y}$ variables that suggests a causal interpretation of the relationship between $\mathrm{X}$ and Y. Additionally, the uses of the formal graphical method are based on the 2-dimensional Cartesian plane, which was introduced in 1637 by René Descartes (Lafleur, 1960), whose contributions to different scientific disciplines, of which economics was only one, were substantial. The 2-dimensional coordinate space opened a new era in economic analysis by providing for analysis of a single economic phenomenon based on the relationship between two variables.

However, it is necessary to mention the major contribution of Antoine Augustin Cournot (1838). Cournot derived the first formula for the rule of supply and demand as a function of price on 2-dimensional view. He was also the first economist to draw supply and demand curves on a graph. Cournot believed that economists must utilize graphs only to establish probable limits and express less-stable facts in more absolute terms. He further held that the practical use of mathematics in economics involves not only strict numerical precision but also graphical visualization. In addition to Cournot and Jevons, other innovative economists who contributed to the analytical graph system in economics over time were Leon Walras (general equilibrium), Alfred Marshall (partial equilibrium) and Joseph Schumpeter (business cycles) (McClelland, 1975). In the 20th century, the use and application of the analytical graphical method among economists were often based on sophisticated mathematical and graphical techniques introduced during the development of new economic models. In particular, calculus, trigonometry, geometry and statistical and forecasting methods began to be employed by economists in constructing their graphs during that time. In addition, 2-dimensional and 3-dimensional Cartesian coordinate systems were also a part of complex economics research (Avondo-Bodino, 1962). Consequently, the application of sophisticated mathematical and graphical techniques can be seen in the development of the following economic models and theories: welfare theory (Hicks, 1939), IS-LM curve (Hansen, 1949), development of static and dynamic analysis (Samuelson, 1947), econometrics (Klein, 1956), Phillips curve (Phillips, 1958), Okun law (Okun, 1975), economic growth theory (Solow, 1956), game theory (Nash, 1950), introduction of dynamic models and econometrics (Tinbergen, 1937), input-output table (Leontief, 1951), monetary theory (Friedman, 1948), and rational expectations theory (Barro, 1991).

The rapid development of the analytical graphical method has been facilitated by high technology and sophisticated analysis instruments, such as the electronic calculator and the computer. The development of analysis instruments in economics took place in two stages. The first stage involved "basic computational instruments" where electronic calculators were used to compute basic mathematical expressions (e.g., long arithmetic operations, logarithm, exponents and squares). This took place between the 1950s and 1960s. The second stage, called "advance computational instruments," took place in the middle of the 1980s. This was when high-speed and storage-capacity computers using sophisticated software were introduced for the first time. The use of sophisticated software enabled easy information management, the application of difficult simulations and the creation of high-resolution graphs under the 3-dimensional coordinate system. These analysis instruments contributed substantially to research and development in economics. Therefore, 
high-performance computational instruments, backed by sophisticated hardware and software, are utilized to create graphical representations with high resolution and accuracy. In fact, the descriptive graphical method and analytical graphical method can be categorized according to function or dimension. In terms of function, these two graphical methods are either descriptive or analytical. In terms of dimension, these two graphical methods can be 2-dimensional, 3-dimensional or multi-dimensional coordinate systems. The descriptive graphical method shows arbitrary information that is used to observe the historical behavior of data from a simple perspective. On the other hand, the analytical graphical method is available to generate time-series graphs, cross-section graphs and scatter diagrams to show the trends and relationships between two or more variables from a multi-dimensional and dynamic perspective.

\section{How do Multi-Dimensional Coordinate Spaces work?}

The main reason to apply multi-dimensional coordinate spaces is to study any economic phenomena from a multidimensional perspective. This is originated by the limitations that the 2-dimensional coordinate space shows at the moment in regard to generating a multidimensional optical visual effect of any economic phenomena in the same graphical space. Hence, multidimensional coordinate spaces lead to an alternative graphical model that is more flexible and innovative than the current 2-dimensional coordinate space for observing multi-variable data behavior. The study of multi-dimensional coordinate spaces requires basic knowledge about "n-dimensional space". The idea of the n-dimensional space originated with Greek thinkers and philosophers such as Socrates, Plato, Aristotle, Heraclitus and Euclid (father of Geometry). The great contribution of Euclid to Geometry was the design of Plane Geometry under 2-dimensional Euclidean Geometry and solid Geometry under 3-dimensional Euclidean Geometry. However, n-dimensional space can be defined as a mental refraction through optical visualization and brain stimulation by several lines in a logical order by length, width, height and colors. Ndimensional space represents the behavior of simple or complex phenomena in different periods of time in the same graphical space.
The study of $\mathrm{n}$-dimensional space is usually based on the application of the "coordinate system". In fact, the coordinate spaces can be classified into 2-dimensional coordinate space, 3-dimensional coordinate space and multi-dimensional coordinate space. The main role of the coordinate system is crucial in the analysis of the relationship between two or more variables, such as exogenous variable(s) and endogenous variable(s), in the same graphical space. In fact, the Euclidean space is given only the mathematical theoretical framework, not the graphical modeling for visualizing the $\mathrm{n}$-dimensions according to different mathematical theoretical research works. On the other hand, Minkowski (Einstein, 1961) introduced the idea of the 4-dimensional space or the "world". The world, according to Minkowski, is originated by the application of the 3-dimensional continuum (or space). The difference between the 4-dimensional space and the 3-dimensional space graphical model is that the first graphical model replaces $(\mathrm{X}, \mathrm{Y}, \mathrm{Z})$ with $\left(\mathrm{X}_{1}, \mathrm{X}_{2}, \mathrm{X}_{3}, \mathrm{X}_{4}\right)$, thus $\mathrm{X}_{1}=\mathrm{X} ; \mathrm{X}_{2}=\mathrm{Y} ; \mathrm{X}_{3}=\mathrm{Z}$ and $\mathrm{X}_{4}=\sqrt{ }-1 . \mathrm{X}_{4}$ is based on the application of the Lorenz transformation axiom. The 4-dimensional space by Minkowski fails to offer a specific graphical modeling or alternative Cartesian coordinate system to help visualize the 4-dimensional space; it only offers a mathematical theoretical framework to describe the idea of 4-dimensional space. Moreover, the application of multi-dimensional coordinate spaces offers a large possibility for adapting n-dimensions, sub-dimensions, micro-dimensions, nano-dimensions and ji-dimensions in the visualization of any economic phenomenon.

In short, the use of coordinate spaces by economists is based on plotting different dots that represent the relationships between two or more variables (endogenous and exogenous) in the first and fourth quadrants in the 2-dimensional coordinate space. The economists proceed to join all of these dots by straight lines until it is possible to visualize histograms, line graphs and scatter plots (see Figure 1). Hence, it is possible to observe the trend and behavior of different variables of any economic phenomenon such as the relationships between unemployment/inflation, interest rate/investment, and prices/quantity demand and supply.

From our point of view, each dot plotted on the 2-dimensional, 3-dimensional and multi-dimensional coordinate spaces represents a single rigid point. In 
fact, the plotting of a single rigid point in any coordinate space requires the application of two basic assumptions: the first assumption is that two rigid points cannot occupy the same space at the same time; the second assumption is that different rigid point(s) deal in different $\mathrm{n}$-dimensional spaces that move under different speeds of time. The variable "time" in the case of multi-dimensional coordinate spaces should be classified by general time, partial time and constant time. General time runs in general-space, but sub-spaces, micro-spaces, and nano-spaces all run under different partial times. In the case of JI-spaces, these are always fixed by constant time.

Recently, a few economists have started to use the 3-dimensional coordinate space in economics by utilizing three axes: "X-coordinate" (or exogenous variable), "Y-coordinate" (or exogenous variable) and the "Z-coordinate" (or endogenous variable). This is based on the construction of surfaces or 3-dimensional manifolds to visualize multi-variable economic data behavior (see Figure 2). According to our research, the use of the 3-dimensional coordinate space is not popular among economists and policy makers.

Based on one thousand five hundred (1500) papers published in twenty-one (21) reputable economics journals ${ }^{1}$ between 1939 and 2012 (JSTOR, 2012), it is possible to observe that the common types of graphical representations applied in the study of social sciences, especially economics, were 2-dimensional coordinate space representations. Of these papers, 99.5\% applied the 2-dimensional Cartesian coordinate system and $0.5 \%$ applied the 3 -dimensional coordinate space system. This study research will proffer several reasons as to $w h y$ economists continue to use the 2-dimensional coordinate space and, sometimes, the 3-dimensional coordinate space systems in the graphical representation of complex and dynamic economic phenomena. These reasons are listed below:

- The 2-dimensional graphical models were established over a long period beginning with the introduction of the 2-dimensional coordinate space by Descartes (Lafleur, 1960). The application of the 2-dimensional coordinate space in the economic graphical analysis has become a tradition.

- The 2-dimensional space is easy to apply in visualizing basic trends or values in the same graphical space. A logical explanation for the common use of the 2-dimensional coordinate space is that it can be easily used to plot, draw and visualize any economic phenomenon. Therefore, the 2-dimensional coordinate space can generate a clear visual and mental reflection for understanding complex and dynamic economic phenomena graphically in the same space and time.

- It is difficult to find alternative and suitable multi-dimensional graphical models to generate the transition from 2-dimensional coordinate space graphical modeling to multi-dimensional space graphical modeling. This research found some difficulties generating this crucial visual and mental transition from 2-dimensional coordinate space to multi-dimensional coordinate space. This could be due to the difficulty of plotting, drawing and visualizing multi-dimensional graphs.

\section{The Traditional Visualization of GDP Behavior from 2-Dimensions:}

The idea of proposing a multi-dimensional graphical modeling approach is to make it possible to visualize the complex and dynamic behavior of different variables that are involved in the construction of the GDP. Therefore, we assume that all of these variables are always in a state of permanent change in the same graphical space. Economists and academics usually continue to visualize the GDP under the application of traditional 2-dimensional graphical modeling using the classic linear graphical trends technique. The linear graphical trends technique can compare the graphical behavior of the GDP by plotting the variable time (daily, weekly, monthly, yearly) on the "X" axis and the GDP growth rate on the "Y" axis to visualize the behavior of GDP across different periods of time (see Figure 3).

On the other hand, the graphical construction of the GDP by the expenditure method using the 2-dimensional graphical modeling approach makes it possible to visualize the aggregate demand curve $(\mathrm{AD})$ that is built by consumption (C), gross investment (I), government spending $(\mathrm{G})$ and net exports $(\mathrm{X}-\mathrm{M})$. Hence, these four macro-variables are fixed on the "Y" axis, and the output (real national income) is fixed on the "X" axis (see Figure 4).

We can observe that in the last two examples of how to draw GDP, both examples only show the use of two 


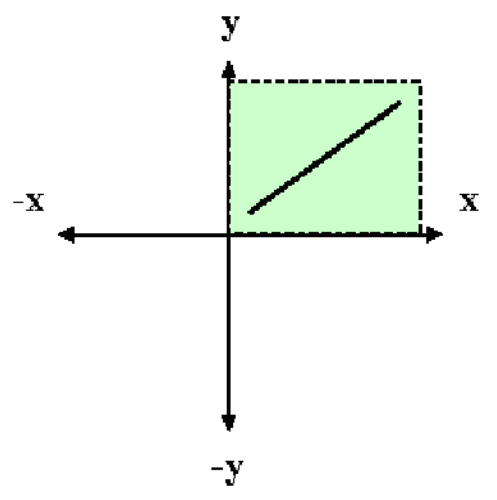

Figure 1.2-Dimensional Coordinate Space

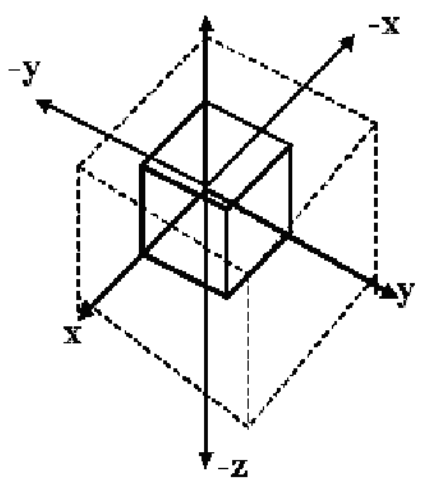

Figure 2. 3-Dimensional Coordinate Space

\section{Gross Domestic Product (GDP)}

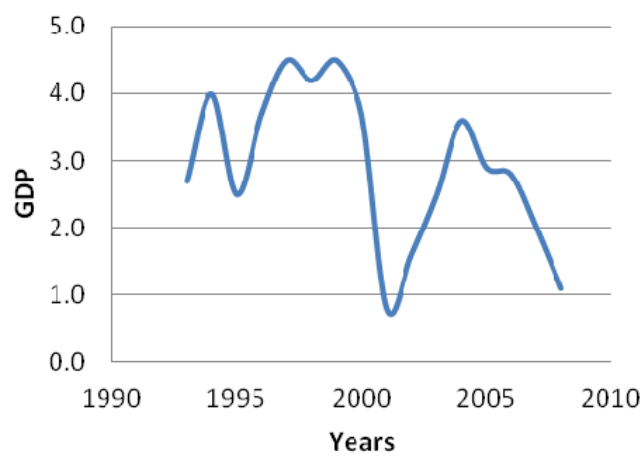

- Gross domestic product (GDP)

Figure 3. Gross Domestic Product Rate Per Year 


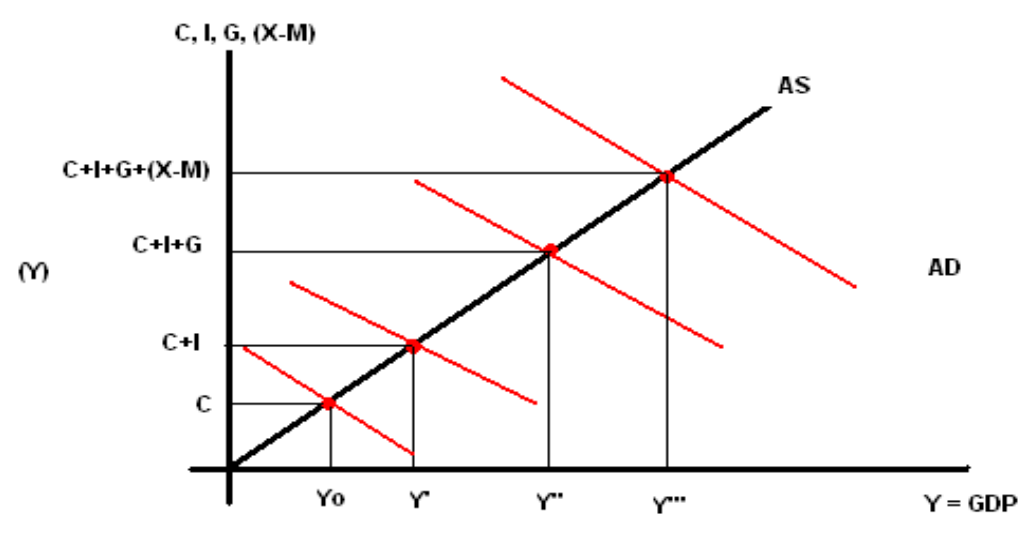

(X)

Figure 4. The Construction of GDP Using the Expenditure Method

axes $(\mathrm{X}, \mathrm{Y})$ to explain the relationship between two variables that interact together in the same graphical space. Consequently, we cannot visualize the interaction of a large number of variables simultaneously within the same graphical space. In fact, the 2-dimensional graphical modeling method does not offer an extra set of axes to plot a large number of variables that are involved in the construction of GDP according to this research. Therefore, the use of multi-dimensional graphical modeling opens new frontiers for visualizing complex and dynamic changes involving a large number of variables simultaneously in the same graphical space. Additionally, multi-dimensional graphical modeling requires the application of graphical modeling in real time to observe, in a much better way, the behavior of all variables in permanent movement distributed in different axes. The classic idea about endogenous and exogenous variables is totally different in multi-dimensional graphical modeling because we are referring to a large number of exogenous variables that interact together, while the endogenous variable becomes a large, single surface located within the same graphical space. We assume that each exogenous variable runs under different speeds of time depending on the rapid input of information in multi-dimensional graphical modeling. The main objective of multidimensional graphical modeling is to monitor a large amount of data that are running in real time. The idea is to visualize unknown and unexpected relationships among different variables involved in the construction of GDP in the same graphical space. The evaluation of results from multi-dimensional graphical modeling differs from traditional 2-dimensional graphical modeling because we do not only visualize the effect of a single exogenous variable on the endogenous variable. Instead, the behavior of a large number of variables running in real time is visualized using different axes (exogenous variables). At the same time, the behavior of the endogenous variable is represented by the general surface.

\section{An Introduction to the 5-Dimensional Coordinate Space}

The 5-dimensional coordinate space consists of five vertical axes: $X_{1}, X_{2}, X_{3}, X_{4}, Y^{*}$. All five axes are distributed by four independent axes, $X_{1}, X_{2}, X_{3}, X_{4}$, and one dependent axis, $Y^{*}$. The $X_{1}, X_{2}, X_{3}, X_{4,} Y^{*}$ axes fix positive and negative real numbers $R_{+/-}$. To plot different values on each axis into the 5-dimensional coordinate space, each value is plotted directly on its axis line. All values plotted on each axis line must be joined together by straight lines until a pyramid-shaped figure is built with five faces in vertical position (see Figure 5 and Prototype 1). Therefore, the $Y^{*}$ axis is positioned in the center of the 


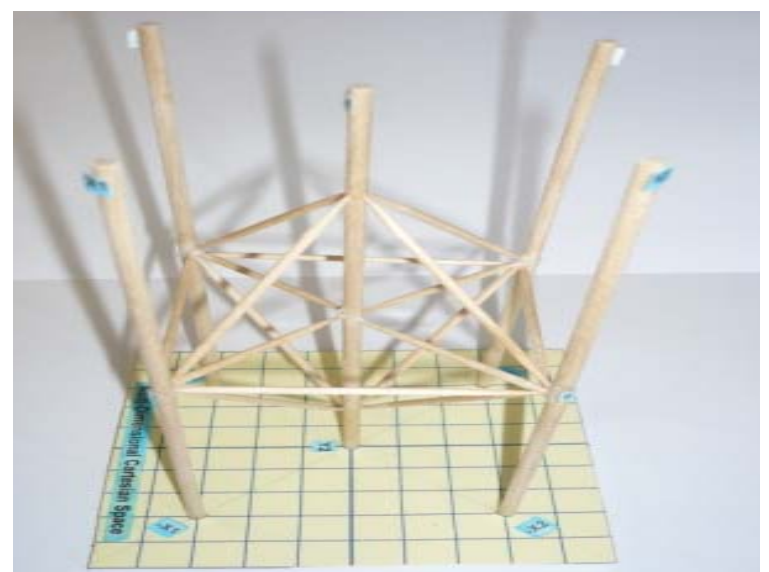

Prototype 1. The 5-Dimensional Coordinate Space

5-dimensional coordinate space (among the other four vertical axes). The $Y^{*}$ axis is the convergent axis of the other four vertical axes, $X_{1}, X_{2}, X_{3}, X_{4}$. The 5-dimensional coordinate system is represented by:

$\left(\left[\mathrm{X}_{1}, \mathrm{X}_{2}, \mathrm{X}_{3}, \mathrm{X}_{4}\right], \mathrm{Y}^{\star}\right)$

\subsection{The Graphical Visualization of U.S. GDP}

\section{Behavior through the Application of the Five-}

\section{Dimensional Coordinate Space:}

The application of the five-dimensional coordinate space is based on the study of U.S. GDP from 1929 to 2004. To study U.S. GDP behavior from a multidimensional perspective, this paper suggests using the GDP-Surface (Ruiz Estrada, 2010). The GDP-Surface is based on the use of the national income growth rate " $\Delta \mathrm{Y}$ " (endogenous variable) and four exogenous variables, which are the consumption growth rate " $\Delta \mathrm{X}_{1}$ ", investment growth rate " $\Delta \mathrm{X}_{2}$ ", government growth rate " $\Delta \mathrm{X}_{3}$ ” and net trade growth rate " $(\mathrm{X}-\mathrm{M})$ $=\Delta \mathrm{X}_{4}$, , shown in the expressions below. For demonstration purposes, the following data are used: consumption growth rate $\left(\Delta \mathrm{X}_{1}\right)$, investment growth rate $\left(\Delta \mathrm{X}_{2}\right)$, government growth rate $\left(\Delta \mathrm{X}_{3}\right)$, net trade growth rate $\left(\Delta \mathrm{X}_{4}\right)$ and the national income growth rate $(\Delta \mathrm{Y})$ of the U.S. from 1928 to 2004 (NBER, 2012). Steps involved in the construction of GDP-Surface are as follows. The general function of the GDP-Surface is equal to:
$\Delta \mathrm{Y}=f\left(\Delta \mathrm{X}_{1}, \Delta \mathrm{X}_{2}, \Delta \mathrm{X}_{3}, \Delta \mathrm{X}_{4}\right)$

To measure each growth rate, the following expressions are used:

$\Delta \mathrm{X}_{1}=\left[\left(\mathrm{X}_{1 \text {-Final period }}\right)-\left(\mathrm{X}_{1-\text {-nitial period }}\right) /\left(\mathrm{X}_{1 \text {-Final period }}\right)\right] \mathrm{x} 100 \%$

$\Delta \mathrm{X}_{2}=\left[\left(\mathrm{X}_{2 \text {-Final period }}\right)-\left(\mathrm{X}_{2 \text {-nnitial period }}\right) /\left(\mathrm{X}_{2 \text {-Final period }}\right)\right] \times 100 \%$

$\Delta \mathrm{X}_{3}=\left[\left(\mathrm{X}_{3 \text {-Final period }}\right)-\left(\mathrm{X}_{3 \text {-nnitial period }}\right) /\left(\mathrm{X}_{3 \text {-Final period }}\right)\right] \times 100 \%$

$\Delta \mathrm{X}_{4}=\left[\left(\mathrm{X}_{4 \text {-Final period }}\right)-\left(\mathrm{X}_{4 \text {-Initial period }}\right) /\left(\mathrm{X}_{4 \text {-Final period }}\right)\right] \times 100 \%$

$\Delta \mathrm{Y}=\left[\left(\mathrm{Y}_{\text {Final period }}\right)-\left(\mathrm{Y}_{\text {Initial period }}\right) /\left(\mathrm{Y}_{\text {Final period }}\right)\right] \times 100 \%$

The GDP-Surface suggests the application of four vectors to show the magnitude and direction of each $\Delta \mathrm{Xi}(\mathrm{i}=1,2,3,4)$ to build the platform of the surface at the bottom of the 5-dimensional coordinate space (vertical position). We have four initial vectors at the ground level of the 5-dimensional coordinate space represented by $\boldsymbol{\ell}_{1}, \boldsymbol{\ell}_{2}, \boldsymbol{\ell}_{3}, \boldsymbol{\ell}_{4}$ (see Figure 6).

$$
\begin{aligned}
& \ell_{1}=\underset{\Delta \mathrm{X}_{1} \Delta \mathrm{X}_{2}}{\longrightarrow} \\
& \ell_{2}=\underset{\Delta \mathrm{X}_{2} \Delta \mathrm{X}_{3}}{\longrightarrow} \\
& \ell_{3}=\overrightarrow{\Delta \mathrm{X}_{3} \Delta \mathrm{X}_{4}} \\
& \ell_{4}=\overrightarrow{\Delta \mathrm{X}_{4} \Delta \mathrm{X}_{1}}
\end{aligned}
$$




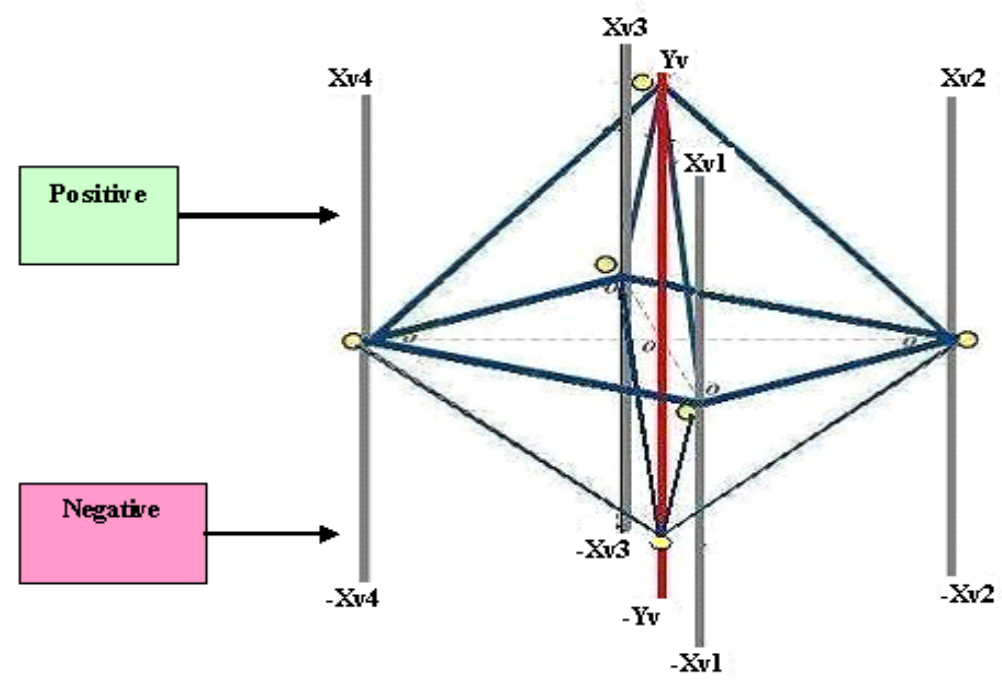

\begin{tabular}{|c|c|c|c|c|}
\hline (Xj:i , Y:i) & (X1:i or -X1:i) & (X2:i or -X2:i) & (X3:i , X3:i) & (X4:i, -X4:i) \\
\hline (Y1:i or -Y1:i) & $(5,1)$ & $(-2,1)$ & $(6,1)$ & $(-5,1)$ \\
\hline
\end{tabular}

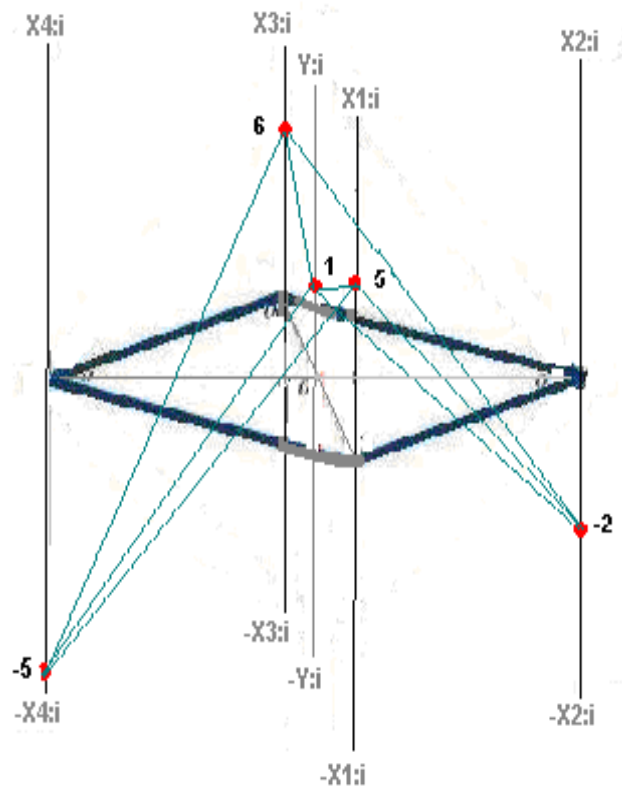

Figure 5. The 5-Dimensional Coordinate Space 


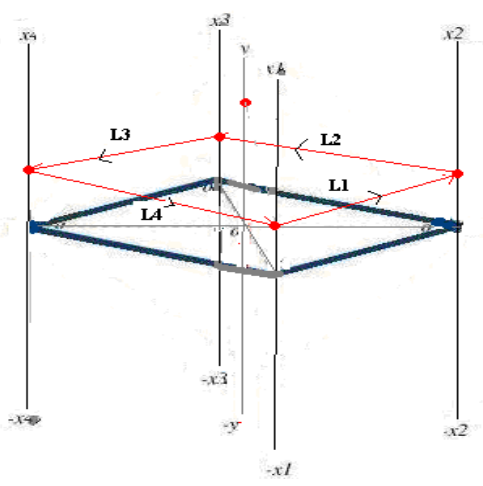

Figure 6. The GDP-Surface Platform

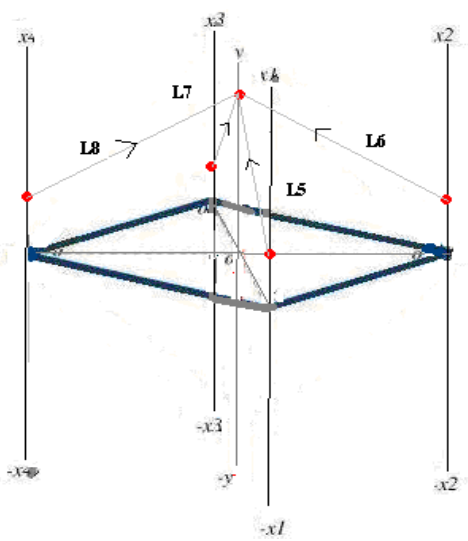

Figure 7. The Main Structure of the GDP-Surface

The next step is to find the vectors to join $\Delta \mathrm{X}_{1}, \Delta \mathrm{X}_{2}$, $\Delta \mathrm{X}_{3}, \Delta \mathrm{X}_{4}$ with $\Delta \mathrm{Y}$ to build the main structure of the GDP-Surface (see Figure 7).

$$
\begin{aligned}
& \ell_{5}=\overrightarrow{\Delta \mathrm{X}_{1} \Delta \mathrm{Y}} \\
& \ell_{6}=\overrightarrow{\Delta \mathrm{X}_{2} \Delta \mathrm{Y}} \\
& \ell_{7}=\overrightarrow{\Delta \mathrm{X}_{3} \Delta \mathrm{Y}} \\
& \ell_{8}=\overrightarrow{\Delta \mathrm{X}_{4} \Delta \mathrm{Y}}
\end{aligned}
$$

Finally, the GDP-Surface is the sum of all vectors from vector $\boldsymbol{\ell}_{1}$ to vector $\boldsymbol{\ell}_{\mathbf{8}}$ (see Figure 8 ).

The GDP-Surface $=\overrightarrow{\ell_{1}+\ell_{2}+\ell_{3}+\ell_{4}+\ell_{5}+\ell_{6}+\ell_{7}+\ell_{8}}$ (5)
The results of the GDP-Surface reflect three possible levels of performance:

\section{Level 1: Stable Macroeconomic Performance}

If the GDP-Surface is located within the positive quadrant of the 5-dimensional coordinate space (vertical position), then the GDP-Surface shows stable macroeconomic performance (see Figure 9).

$+\Delta \mathrm{Y}=f\left(+\Delta \mathrm{x}_{1,}+\Delta \mathrm{x}_{2,}+\Delta \mathrm{x}_{3},+\Delta \mathrm{x}_{4}\right)$

\section{Level 2: Unstable Macroeconomic Performance}

If the GDP-Surface is located between the positive and negative quadrant of the 5-dimensional coordinate space, then the GDP-Surface shows unstable macroeconomic performance (see Figure 10). 


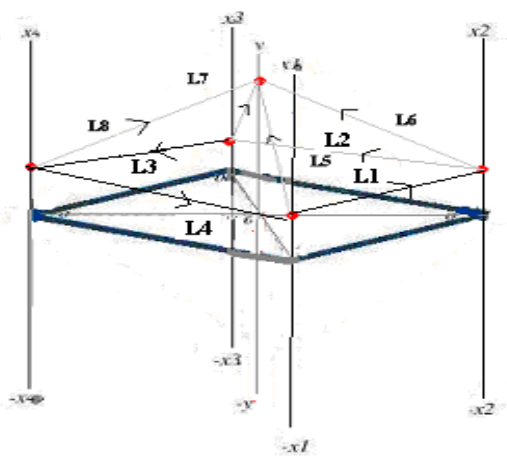

Figure 8. The GDP-Surface

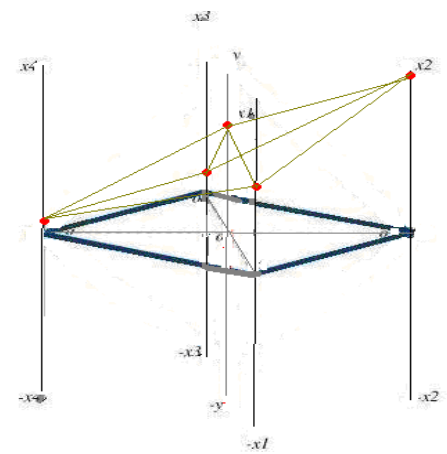

Figure 9. GDP-Surface: Stable Macroeconomic Performance

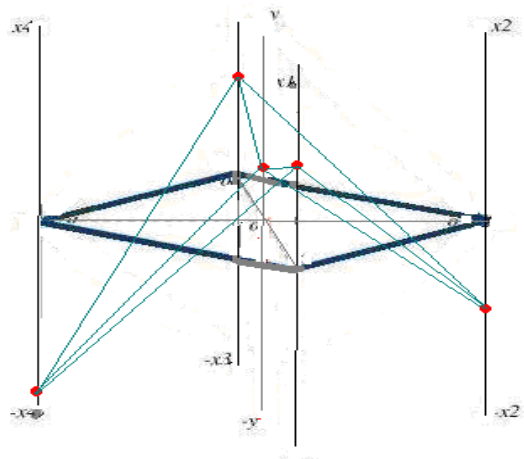

Figure 10. GDP-Surface: Unstable Macroeconomic Performance 


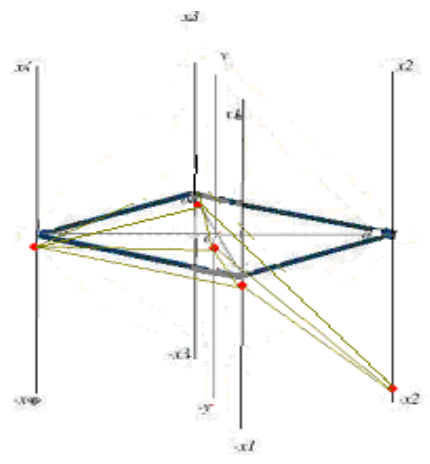

Figure 11. GDP-Surface: Poor Macroeconomic Performance

$+/-\Delta \mathrm{Y}=f\left(+/-\Delta \mathrm{x}_{1,}+/-\Delta \mathrm{x}_{2,}+/-\Delta \mathrm{x}_{3},+/-\Delta \mathrm{x}_{4}\right)$

\section{Level 3: Poor Macroeconomic Performance}

If the GDP-Surface is located in the negative quadrant or is equal to zero of the 5-dimensional coordinate space (vertical position), then the GDP-Surface shows poor macroeconomic performance (see Figure 11).

$-\Delta \mathrm{Y}=f\left(-\Delta \mathrm{x}_{1,}-\Delta \mathrm{x}_{2,}-\Delta \mathrm{x}_{3},-\Delta \mathrm{x}_{4}\right)$ or $0=f(0,0,0,0)$

\subsection{GDP-Surface: U.S. GDP Behavior from 1928 to 2004}

The GDP-Surface shows how the national income growth rate " $\Delta \mathrm{Y}$ " or endogenous variable is simultaneously affected by four exogenous variables: consumption growth rate " $\Delta \mathrm{X}_{1}$, investments growth rate " $\Delta \mathrm{X}_{2}$ ", government growth rate " $\Delta \mathrm{X}_{3}$ " and net trade growth rate " $(\mathrm{X}-\mathrm{M})=\Delta \mathrm{X}_{4}$ ”. All variables move along their respective axes simultaneously on the same 5-dimensional coordinate space (vertical position). The GDP-Surface shows how the consumption growth rate $\left(\Delta \mathrm{X}_{1}\right)$, investment growth rate $\left(\Delta \mathrm{X}_{2}\right)$, government growth rate $\left(\Delta \mathrm{X}_{3}\right)$, net trade growth rate $\left(\Delta \mathrm{X}_{4}\right)$ and the national income growth rate $(\Delta \mathrm{Y})$ of the U.S. move in different directions simultaneously within the 5-dimensional coordinate space (vertical position). If we observe the U.S. GDP-Surface period by period from 1928 to 2004 (NBER, 2012), the GDP-Surface shows different displacements within the 5-dimensional coordinate space (vertical position).
Between 1928 and 2004, the U.S. GDP-Surfaces at Level 1 or stable macroeconomic performance are located within forty periods: 1933/34, 1934/35, 1935/36, 1936/37, 1938/39, 1939/40, 1940/41, 1942/43, 1947/48, 1950/51, 1954/55, 1955/56, 1958/59, 1959/60, 1960/61, $1962 / 63,1963 / 64,1967 / 68,1968 / 69,1969 / 70,1970 / 71$, 1971/72, 1972/73, 1973/74, 1974/75, 1975/76, 1976/77, 1977/78, 1981/1982, 1982/1983, 1983/1984, 1984/85, 1985/86, 1986/87, 1991/1992, 1992/1993, 1993/1994, 1995/96, 1996/97 and 1998/1999 (see Figure 7). Level 1 or stable macroeconomic performance is characterized by positive results in all four broad categories of spending $\left(\Delta \mathrm{X}_{1}, \Delta \mathrm{X}_{2}, \Delta \mathrm{X}_{3}, \Delta \mathrm{X}_{4}\right)$ and the national income growth rate $(\Delta \mathrm{Y})$.

The U.S. GDP-Surfaces at Level 2 or unstable macroeconomic performance are located in forty periods: 1928/29, 1929/30, 1930/31, 1931/32, 1932/1933, 1937/38, 1941/42, 1942/43, 1943/44, 1944/45, 1945/46, $1946 / 47,1947 / 48,1948 / 49,1949 / 50,1951 / 52,1952 / 53$, 1953/54, 1956/57, 1957/58, 1961/62, 1964/65, 1965/66, 1966/67, 1967/68, 1978/79, 1979/80, 1980/81, 1982/83, 1987/88, 1988/89, 1989/90, 1990/91, 1994/95, 1997/98, 1999/2000, 2000/01,2001/02, 2002/03 and 2003/04 (see Figure 12). The GDP-Surfaces at Level 2 or unstable macroeconomic performance is characterized by non-proportional results, comprising both positive and negative growth rate values. Therefore, the unstable macroeconomic performance does not necessarily generate a negative impact on the national income growth rate " $\Delta \mathrm{Y}$ " in the long term. If we gener- 
U.S. GDP_Surface 1929/30

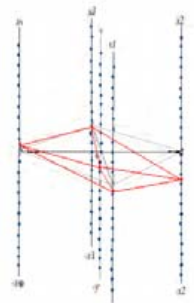

U.S. GDP surface 1933/34

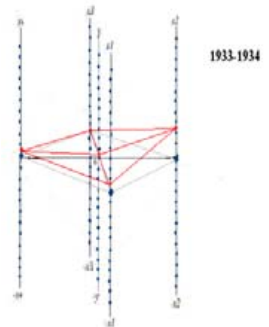

U.S. GDP Surface 1960/61

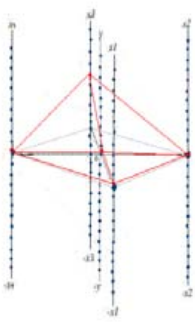

1959.196

U.S. GDP Surface 2000/01

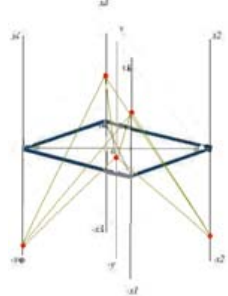

U.S. GDP_Surface 1930/31

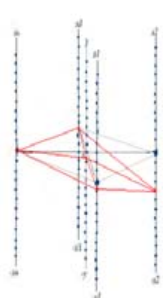

U.S. GDP surface 1934/35
U.S. GDP Surface 1931/32

U.S. GDP ${ }_{\text {Surface 1932/33 }}$

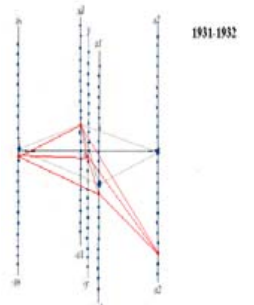

U.S. GDP Surface 1940/41 U.S. GDP Surface 1950/51
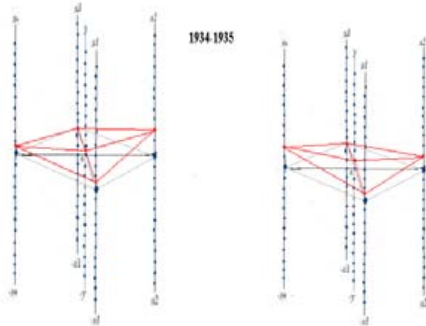

194-1941

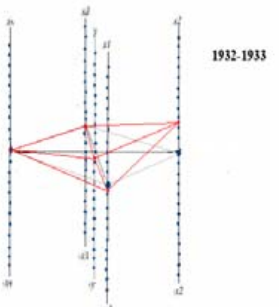

U.S. GDP Surface 1970/71

U.S. GDP surface 1980/81 U.S. GDP surface 1990

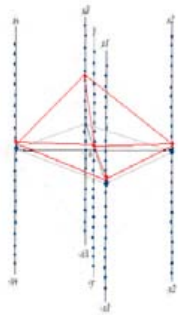

1970-1971
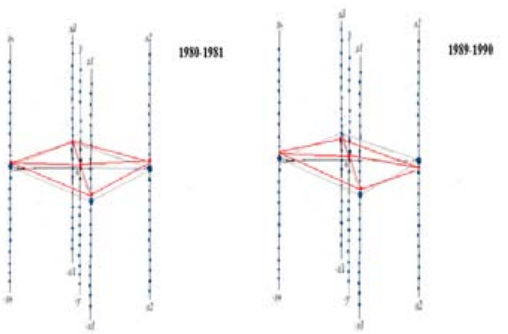

U.S. GDP Surface 2001/02

U.S. GDP Surface 2002/03

U.S. GDP surface 2003
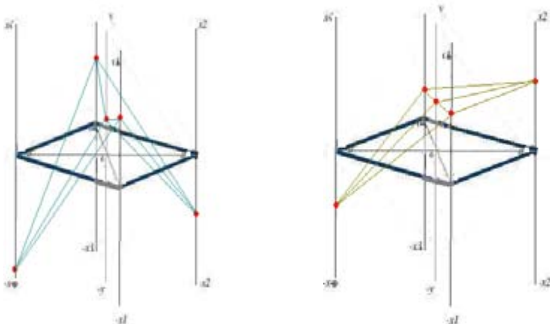

Figure 10. United States GDP-Surface from 1929 to 2004

Source: The National Bureau of Economic Research -NBER- Electronic Report (2012) 



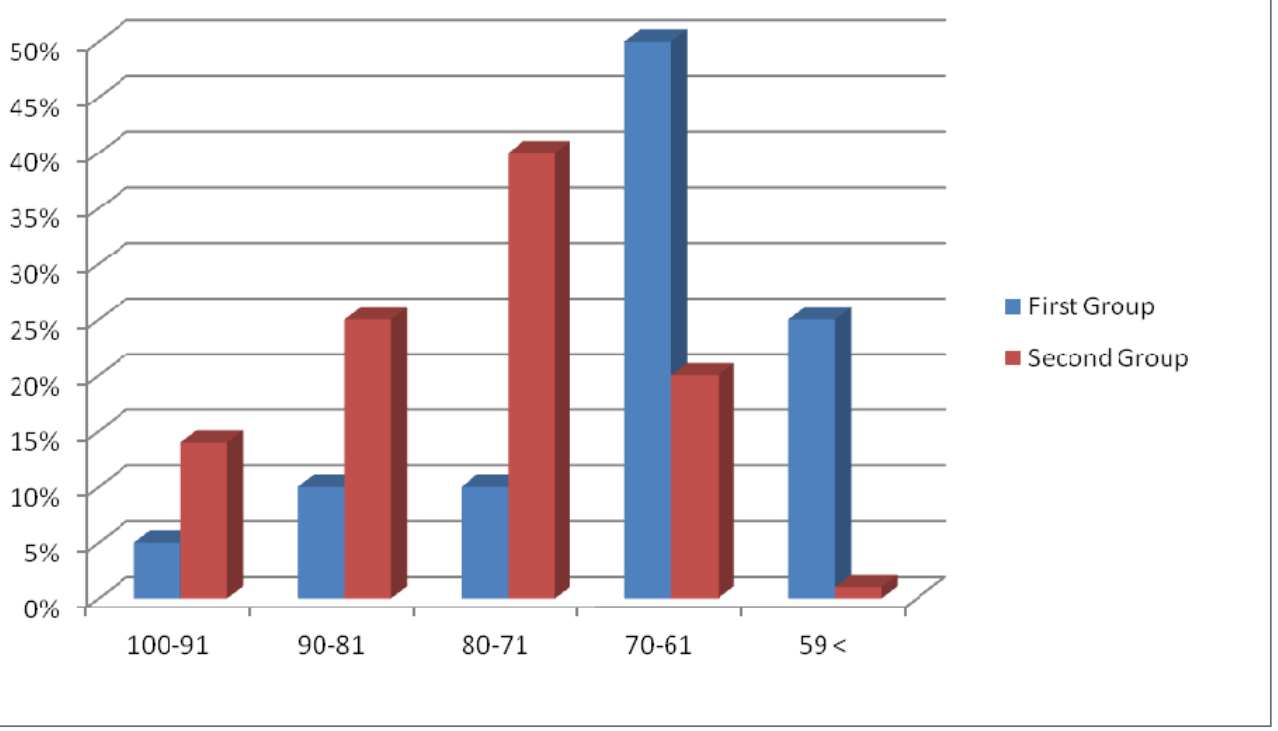

Figure 13. Final Results With and Without Didactic Materials and E-Learning

of systematic teaching techniques and methods, such as prototypes and E-learning. Moreover, the positive performance attributed to the teaching and learning of multidimensional graphs also depends on five basic premises, which are as follows:

1. Basic knowledge of plotting and drawing 2-dimensional graphs on the Cartesian coordinate system.

2. Basic knowledge of Euler's geometry.

3. A basic idea of time and space in the graphical space.

4. The construction of solid prototype(s) (Ruiz Estrada, 2009) using basic materials, such as wood, paper and plastic.

5. The ability to learn about and understand the different dimensions that exist in multidimensional graphs.

After we taught the theoretical framework of basic multidimensional graphs, we provided to our students basic examples and different applications of multidimensional graphs in real economic cases. Until today, the basic 2-dimensional graphs usually applied in economics had been the focus of our teaching, but at the end of the class session, we gave some basic examples on how the same problems can be visualized from a multidimensional perspective.

\subsection{Pros and Cons of the Uses of Multidimensional Graphical Methods in Economics}

In light of the results, significant pros are observed in the use of multidimensional graphical methods in economics that show the advantage in visualizing a large series of variables moving simultaneously in the same graphical space without any visual restriction. Additionally, the use of multidimensional graphical methods expands the horizons of students and increases their curiosity in complex and dynamic economic phenomena from a multidimensional perspective. Based on our experience, the teaching and learning of multidimensional graphs allows us to explain to our students that the basic facts for observing complex and dynamic economic phenomena cannot only depend on the visualization of a simple point that is moving up and down in two dimensions (which explains the behavior of several variables that can affect GDP behavior as a whole). In effect, the learning of multidimensional graphical methods in economics requires great effort from the teaching side, particularly in improving the methods and techniques that facilitate the easy learning of multidimensional graphs in the classroom. The cons observed are few. 
Therefore, the preparation of prototypes and E-learning materials that enhance the teaching and learning of multidimensional graphs is imperative.

\section{Conclusion}

This paper concludes that it is possible to use multidimensional graphical methods in the teaching and learning of economics. Success in learning and teaching multidimensional graphs directly depends on the effort of the lecturer or researcher who prepares prototypes to be used by students as well as on the application of E-learning tools such as homepages designed for the specific topic. This paper argues that multi-dimensional graphs could open a new era in economic analysis from a microeconomic and macroeconomic perspective, particularly as it is now possible to observe dynamic and complex economic phenomena through time and space in the same graphical space. As such, we can conclude that the extension of more than two dimensions and three dimensions implies the use of sub-coordinates and a new multidimensional graphical framework to learn more about the visualization of a large number of variables that can affect GDP behavior from an unconventional perspective. Finally, this paper offers a new multi-dimensional coordinate space for economists, academics and policy makers to facilitate the visualization of multi-variable economic data in the same graphical space and time. Moreover, the idea for proposing a new multi-dimensional coordinate space is appropriate given the limitations associated with the 2-dimensional Cartesian coordinate plane and the 3-dimensional coordinate space that restricts visualization of multi-variable economic data behavior in the same graphical space and time.

\section{References}

Avondo-Bodino, G. (1962). Economic Applications of the Theory of Graphs. New York, NY: Gordon \& Breach Publishing Group.

Barro, R. (1991). Economic Growth in a Cross Section of Countries. Quarterly Journal of Economics, 106 (2), 407-443.

Beniger, J. R., \& Robyn, D. L. (1978). Quantitative Graphics in Statistics: A Brief History. The American Statistician, 32(1), 1-11.

Cournot, A. (1838). Mémoire Sur Les Applications du Calcul des Chances à la Statistique Judiciaire [The application of the calculus of probability to judi- cial statistics]. Journal Des Mathématiques Pures et Appliquées, 12 (3), 257-334.

Edgeworth, F. Y. (1888). New Methods of Measuring Variation in General Prices. London, UK: Journal of the Royal Statistics Society.

Econographication Virtual Laboratory. (2012). E-Lab Section. Retrieved from http://www.econographication.com

Einstein, A. (1961). Relativity: The Special and the General Theory (3rd ed.). New York, NY: Three Rivers Press.

Friedman, M. (1948). A Monetary and Fiscal Framework for Economic Stability. The American Economic Review, 38 (3), 245-264.

Gordon, D. F. (1965). The Role of the History of Economic Thought in the Understanding of Modern Economic Theory. The American Economic Review, 55 (1-2), 119-127.

Hansen, A. (1949). Monetary theory and Fiscal Policy. New York, NY: McGraw-Hill Co.

Hicks, J. R. (1939). The Foundations of Welfare Economics. Economic Journal, 49 (196), 696-712.

Jevons, W. (1862). On the Study of Periodic Commercial Fluctuations. London, UK: Report of BAAS.

JSTOR. (2012). Database of Journals in Economics. Available at http://www.jstor.org

Klein, L. (1956). The Efficiency of Estimation in Econometric Models (Working Papers No. 157). Cowles Foundation. Retrieved from http://cowles.econ. yale.edu/P/cp/p01b/p0157.pdf

Lafleur, L. (1960). Discourse on Method, Optics, Geometry, and Meteorology. New York, NY: The Liberal Arts Press.

Leontief, W. (1951). The Structure of America Economy 1919-1939 (2 $2^{\text {nd }}$ ed.). New York, NY: Oxford University Press.

Maas, H. (2005). William Stanley Jevons and the Making of Modern Economics. Cambridg, UK: Cambridge University Press.

McClelland, P. (1975). Causal Explanation and Model Building in History, Economics, and the New Economic History. New York, NY: Cornell University Press.

Nash, J. (1950). The Bargaining Problem. Econometrica, 18 (2), 155-162.

NBER. (2012). Statistics section. Available at http:// www.nber.org/ 
National Bureau of Economic Research - NBER (2012). Electronic Statistics Report. Available at http:// www.nber.org/

Okun, A. (1975). Equality and Efficiency: The Big Tradeoff. Washington, DC: The Brookings Institution.

Phillips, A. W. (1958). The Relation between Unemployment and the Rate of Change of Money Wage Rates in the United Kingdom, 1861-1957. Economica, 25 (100), 283-299.

Playfair, W. (2005). The Commercial and Political Atlas and Statistical Breviary. Cambridge, UK: Cambridge University Press.

Ruiz Estrada, M. A. (2007). Econographicology. International Journal of Economics Research, 4 (1), 75-86.

Ruiz Estrada, M. A. (2009). The Application of Prototypes in the teaching-learning Process of Multidimensional Physical Spaces (Working Paper No. 2009-3). Faculty of Economics and Administration. University of Malaya.

Ruiz Estrada, M. A. (2010). GDP-Surface. International Journal of Economics Research, 6 (3), 295-307.

Ruiz Estrada, M. A. (2011). Multi-dimensional Coordinate Spaces. International Journal of Physical Sciences, 6 (3), 340-357.

Samuelson, P. (1947). Foundations of Economic Analysis. Cambridge, MA: Harvard University Press.

Solow, R. (1956). A Contribution to the Theory of Economic Growth. Quarterly Journal of Economics, 70 (1), 65-94.

Timbergen, J. (1937). An Econometrics Approach to Business Cycle Problems. Paris: Herman \& Cie Publisher. 